\title{
A new analytical cut-off point for determining 18 years of age using MRI on medial clavicular epiphysis
}

\author{
Roberto Scendoni $^{\text {a, }, \text { Isabella Lima Arrais Ribeiro }}{ }^{\mathrm{b}}$, Mariano Cingolani ${ }^{\mathrm{a}}$, Andrea Giovagnoni ${ }^{\mathrm{c}}$, \\ Martina Curzi ${ }^{\mathrm{c}}$, Piergiorgio Fedeli ${ }^{\mathrm{d}}$, Roberto Cameriere ${ }^{\mathrm{e}, \mathrm{f}}$ \\ ${ }^{a}$ Department of Law, Institute of Legal Medicine (AgEstimation Project), University of Macerata, Macerata, Italy \\ ${ }^{\mathrm{b}}$ Postgraduate Program in Dentistry, Federal University of Paraíba, Campus I, João Pessoa, PB 58051900, Brazil \\ ${ }^{\mathrm{c}}$ Department of Radiological Sciences, Ospedali Riuniti, Marche Polytechnic University, Ancona, Italy \\ ${ }^{\mathrm{d}}$ School of Law, Legal Medicine, University of Camerino, Camerino, Italy \\ ${ }^{\mathrm{e}}$ Department of Forensic Medicine, IM Sechenov First Moscow State Medical University, Moscow, Russian Federation \\ ${ }^{\mathrm{f}}$ AgEstimation Project, Department of Forensic Medicine, University of Molise, Italy
}

\section{A R T I C L E I N F O}

\section{Keywords:}

Age estimation

Magnetic resonance imaging

18 years

Medial clavicular epiphysis

Cut-off point

Logistic regression

\begin{abstract}
A B S T R A C T
Evaluation of the ossification of the medial clavicular epiphysis plays a key role in forensic age estimation. The purpose of the present study was to assess a new numerical cut-off at the age of 18 years, taking into consideration Magnetic Resonance (MR) images of the medial clavicular epiphysis. We analyzed 163 MR scans of Italian subjects aged between 14 and 25 years. Using the data obtained we calculated two ratios: REM-1 (ratio between the length of the whole epiphysis and the length of the metaphysis) and REM-2 (ratio between the length of epiphyseal-metaphyseal fusion and the length of the metaphysis). In 68 out of 163 cases it was not possible to measure REM-2. The reproducibility was demonstrated using the Intraclass Correlation Coefficient (ICC) (Cronbach's alpha > 0.80). REM-1 and REM-2 were compared in each category of age (adult and minor) by the Wilcoxon signed-rank test. The cut-off points for measurements of REM-1 and REM-2 were determined by logistic regression. For REM-1, the cut-off scores were 0.83 for all individuals (accuracy $=94.77 \%$ ) and males (accuracy $=96.05 \%$ ), and 0.86 for females (accuracy $=92.30 \%$ ). For REM-2, the cut-off values were 0.40 for all individuals and males (accuracy $=100.00 \%$ ), and 0.41 for females (accuracy $=100.00 \%$ ). Finally, receiver operating characteristic (ROC) curves for age classification based on REM-1 and REM-2 were constructed, showing that REM-2 had the highest discriminative power. Thus, a new cut-off model for predicting the age of majority has been introduced, conducting a quantitative analysis thanks to the use of a high-resolution imaging tool.
\end{abstract}

\section{Introduction}

Age estimation of living individuals is a relatively recent area of investigation that is becoming increasingly relevant in various fields of both forensic medicine and international law, especially in the definition of minors and adults [1].

One of the main reasons for this is related to migration issues and the identification of refugees; the fact that migrants often lack documents showing their correct birth dates complicates the work of immigration services, and the problem is compounded when it comes to borderline situations where it is unknown whether or not an individual has reached the age of majority. Current multifactorial age estimation methods are widely based on radiography, mainly using the hand/wrist area [2]. Another frequent approach relies on panoramic dental X-rays, even if new methods, tested on large populations, focus on the development of the third molar at one side of the mandible [3].

Evaluation of the ossification of the medial clavicular epiphysis plays a key role in forensic age estimation, particularly in determining whether the age of 18 has been attained. Traditional radiography has been used as a tool to estimate the 21st year of age by Schmeling et al. [4]. This paper looks at the use of Magnetic Resonance Imaging (MRI) for evaluating the developmental state of the medial clavicular epiphysis. In forensic age estimation there is growing interest in using MRI to avoid exposure to ionizing radiation, and over the last decade much

\footnotetext{
* Corresponding author at: Postal address: Via Don Minzoni, 9, 62100 Macerata, Italy.

E-mail address: r.scendoni@unimc.it (R. Scendoni).
} 
research has been conducted on MRI techniques for visualizing and analyzing different anatomical categories [5-7]. Indeed, this approach makes it possible to avoid the prohibitions imposed by the authorities of different states regarding age estimation for non-clinical purposes. Although the procedure incurs higher costs than X-rays, MRI is capable of detailed analysis of the development of ossification.

The first MRI study on the degree of ossification of the medial clavicular epiphysis was published in 2007 by Schmidt et al. [8]. Considering the Kellinghaus substage system [9], the bridge stages found at 18 years of age (considering the mean values) are: Stage 2a (the lengthwise epiphyseal measurement is one third or less compared to the widthwise measurement of the metaphyseal ending) and Stage $2 b$ (the lengthwise epiphyseal measurement is over one third to two thirds compared to the widthwise measurement of the metaphyseal ending) for males; and stage $2 \mathrm{c}$ (the lengthwise epiphyseal measurement is over two thirds compared to the widthwise measurement of the metaphyseal ending) and Stage 3a (the epiphyseal-metaphyseal fusion completes one third or less of the former gap between epiphysis and metaphysis) for females. In 2012, Cameriere et al. [10] published an article in which the validity of Schmeling's method for determining 18 years of age by assessing clavicular development was tested. In recent years, the same Cameriere et al. have studied various anatomical areas to determine whether or not a subject has reached a legally important age. In particular, with regard to the 18-year threshold, they have focused on analyses of the lower third molar, defining a cut-off value. This therefore represents a shift from previous qualitative techniques towards a quantitative analysis, which yields easily comparable numerical results.

In the light of this, the aim of the present study is to assess a new metric cut-off point at the age of 18 years by analyzing MR images of the medial clavicular epiphysis, in order to discriminate whether or not an individual has reached the age of majority.

\section{Materials and methods}

The subjects of this retrospective study underwent MRI of the chest between 2012 and 2021 and were selected from the database of the Radiology Department of the "Ospedali Riuniti" of Ancona - Polytechnic University of Marche. Measurements were performed on the left clavicle. Inclusion criteria were males and females aged between 14 and 25 years. Exclusion criteria included growth diseases, endocrine disorders or osteodystrophy. The final study cohort was composed of 163 Italian subjects ( 84 males and 79 females). The sex and age distribution of the sample can be observed in Table 1 .

The exported images were anonymized, considering only the sex and age of the subject at the time of the MRI scan. Each MRI was obtained by a 1.5 T scanner (GE Signa, Excite HDxt, software version 15.0) with an 8channel surface coil. Patients were placed in a supine position with their arms by their side. All images were generated using T1-weighted turbo spin-echo sequences in the coronal plane (TR/TE 400-600/15-25; echo train length of 10 ; field of view $170 \times 190$; slice thickness $3 \mathrm{~mm}$; gap 0.3

Table 1

Distribution of the sample according to sex and age $(n=163)$.

\begin{tabular}{llll}
\hline Age (years) & Female & Male & Total \\
\hline 14 & 5 & 5 & 10 \\
15 & 7 & 11 & 18 \\
16 & 12 & 18 & 30 \\
17 & 13 & 11 & 24 \\
18 & 9 & 11 & 20 \\
19 & 7 & 5 & 12 \\
20 & 5 & 4 & 9 \\
21 & 9 & 5 & 14 \\
22 & 5 & 6 & 11 \\
23 & 3 & 2 & 5 \\
24 & 4 & 4 & 8 \\
25 & 0 & 2 & 2 \\
Total & 79 & 84 & 163 \\
\hline
\end{tabular}

mm; number of excitations: 2 ; $320 \times 320$ matrix). For each MRI examination, an expert radiologist with at least eight years' experience in musculoskeletal MRI evaluation selected the image in which the medial portion of clavicle was most clearly visible, allowing the lengths of the epiphysis and metaphysis to be measured. The anatomical landmark was the sternoclavicular joint.

The MRIs were processed using ImageJ, a computer-aided image processing program [11]. Using the Kellinghaus substage system, for each MR image, the following indicators were calculated using the 'Straight Line' ImageJ function:

a) the length of the metaphysis (Fig. 1A)

b) the length of the whole epiphysis (Fig. 1B)

c) the length of epiphyseal-metaphyseal fusion (Fig. 1C)

Finally, we calculated two ratios:

1) REM-1 = ratio between the length of the whole epiphysis and the length of the metaphysis.

2) REM-2 = ratio between the length of epiphyseal-metaphyseal fusion and the length of the metaphysis.

The full data were saved by the software in a file in excel format.

\subsection{Statistical analysis}

The reliability and the reproducibility was assessed from the same data from two examiners. The Intraclass Correlation Coefficient (ICC) were performed and the value of Cronbach's alpha were evaluated.

If the length of the epiphyseal-metaphyseal fusion was not clearly delineated in a subject due to image defects, the two observers agreed not to proceed with the measurements, thus excluding it from statistical analysis.

The real age was classified as a binary variable, divided into adults ( 18.00 or more years old), and minors ( $0-17.99$ years old). To check that the REM-1 and REM-2 variables were normally distributed we ran Kolmogorov-Smirnov and Shapiro-Wilk tests, and a non-normal distribution ( $\mathrm{p}<0.05$ ) was confirmed. REM-1 and REM-2 were compared in each category of age (adult and minor) by conducting the Wilcoxon signed-rank test and evaluating possible differences between measurements.

Logistic regression was used to calculate the cut-off points for measurements of REM-1 and REM-2 depending on the highest levels of sensitivity and specificity. Individuals were sequentially classified as adults or minors using cross-validation analysis, according to measurements obtained. Then estimated classifications based on REM-1 and REM-2 were compared to real classifications. For all comparisons between classifications, contingence tables (confusion matrices) were generated, along with the predictive values of sensitivity, specificity, positive predictive value, negative predictive value, positive likelihood, negative likelihood and accuracy of estimates.

All statistical analyses were performed using the R [12] and IBM SPSS [13] software packages, selecting a significance level of $5 \%$.

\section{Results}

As regards reproducibility, in Table 2 is possible to observer the intra and inter-examiner analysis (from Intraclass Correlation Coefficient), indicating that the method used in this study, considering each of measurements, was reliable and reproducible.

REM- 2 could not be calculated in 68 of the 163 individuals evaluated. In all of these cases the individuals were minors, with a median age of $15.24(16.30 ; 16.90)$ years old.

REM-1 $(\mathrm{n}=163)$ ranged from 0.40 to $0.96 \mathrm{~mm}$ and REM-2 $(\mathrm{n}=95)$ ranged from 0.11 to $0.96 \mathrm{~mm}$. The distribution of the sample according to sex and median age for each group of measurements for REM-1 and 


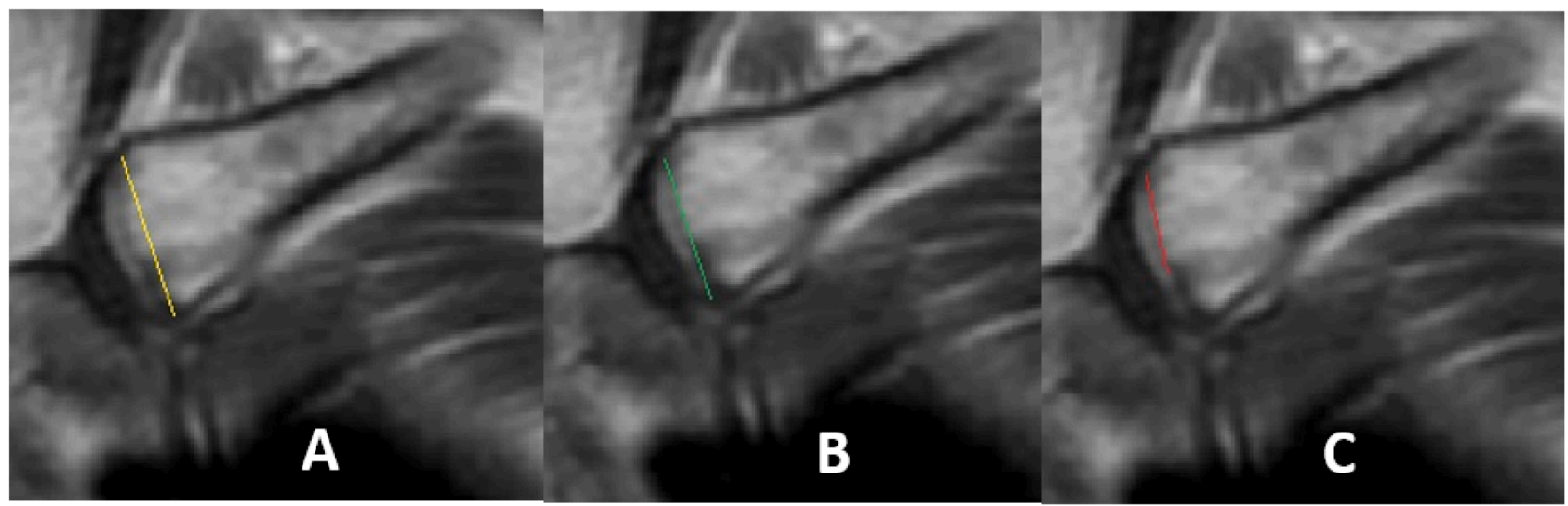

Fig. 1. Coronal T1-weighted TSE image of sternoclavicular joint. A: length of the metaphysis (yellow line); B: length of the whole epiphysis (green line); C: length of epiphyseal-metaphyseal fusion (red line).

Table 2

Intra- and inter-examiner analysis for interest variables for the study.

\begin{tabular}{lll}
\hline Variable & Cronbach's alpha Intra-examiner & Cronbach's alpha Inter-examiner \\
\hline Metaphysis & 0.999 & 0.999 \\
Epiphysis & 0.999 & 0.858 \\
Fusion & 0.999 & 0.998 \\
REM-1 & 0.997 & 0.906 \\
REM-2 & 0.999 & 0.999 \\
\hline
\end{tabular}

Intraclass Correlation Coefficient (ICC) (Cronbach's alpha). Significance level = $5 \%$.

\section{REM-2 are described in Table 3.}

As shown in Table 4, the general and sex-separated samples were evaluated considering the median real age, and REM- 1 and REM- 2 were compared by categories, "adult" and "minor".

The optimal cut-off points in logistic regression were determined for REM-1 and REM-2. For REM-1 the optimal cut-off values were 0.83 for all individuals (accuracy $=94.77 \%$ ) and males (accuracy $=96.05 \%$ ) and 0.86 for females (accuracy $=92.30 \%$ ). For REM-2, the optimal cut-off scores were 0.40 for all individuals and males (accuracy $=100.00 \%$ for both) and 0.41 for females (accuracy $=100.00 \%$ ). Values equal to or above these cut-off points were used to classify individuals as adults, while values below classified individuals as minors. In cases where it was not possible to obtain REM-2, individuals were classified as minors.

The relationship between chronological age and REM-1 and REM-2 age classifications (divided into all individuals, male and female sex) is reported in Fig. 2.

In Fig. 3, receiver operating characteristic (ROC) curves for age

Table 3

Descriptive statistics for age and sex distribution of REM-1 $(n=163)$ and REM-2 $(\mathrm{n}=95)$.

\begin{tabular}{|c|c|c|c|c|c|c|}
\hline \multirow[b]{2}{*}{ REM-1 } & \multirow[b]{2}{*}{ Female } & \multicolumn{2}{|l|}{ Age } & \multirow[t]{2}{*}{ Male } & \multicolumn{2}{|l|}{ Age } \\
\hline & & Median & (Q1; Q3) & & Median & (Q1; Q3) \\
\hline $0.15-0.39$ & 0 & - & - & 0 & - & - \\
\hline $0.40-0.79$ & 33 & 16.62 & $\begin{array}{l}\text { (15.18; } \\
17.13)\end{array}$ & 40 & 16.27 & $\begin{array}{l}(15.35 \\
16.70)\end{array}$ \\
\hline $0.80-0.97$ & 46 & 20.12 & $\begin{array}{l}(18.71 \\
22.22)\end{array}$ & 44 & 20.24 & $\begin{array}{l}(18.51 ; \\
22.50)\end{array}$ \\
\hline \multicolumn{7}{|l|}{ REM-2 } \\
\hline $0.15-0.39$ & 3 & 17.54 & $\begin{array}{l}(17.24 \\
17.54)\end{array}$ & 11 & 17.63 & $\begin{array}{l}(17.42 \\
17.87)\end{array}$ \\
\hline $0.40-0.79$ & 17 & 18.88 & $\begin{array}{l}\text { (18.61; } \\
19.49)\end{array}$ & 27 & 19.76 & $\begin{array}{l}(18.63 ; \\
21.03)\end{array}$ \\
\hline $0.80-0.97$ & 25 & 21.98 & $\begin{array}{l}\text { (21.29; } \\
23.39)\end{array}$ & 12 & 23.89 & $\begin{array}{l}(22.89 \\
24.92)\end{array}$ \\
\hline
\end{tabular}

Legend: Q1 = 1st quartile; Q3 = 3rd quartile.
Table 4

Characterization of study sample and comparison between measurements of REM-1 and REM-2.

\begin{tabular}{|c|c|c|c|c|c|}
\hline Group & Real age & $\begin{array}{l}\text { Real age } \\
\text { Median (Q1; } \\
\text { Q3) }\end{array}$ & $\begin{array}{l}\text { REM-1 } \\
\text { Median (Q1; } \\
\text { Q3) }\end{array}$ & $\begin{array}{l}\text { REM-2 } \\
\text { Median (Q1; } \\
\text { Q3) }\end{array}$ & $\mathrm{p}$ \\
\hline \multirow[t]{2}{*}{ General } & $\begin{array}{l}\text { Adult } \\
\text { (n=81; } \\
\text { REM-1) } \\
\text { Adult } \\
\text { (n=81; } \\
\text { REM-2) }\end{array}$ & $\begin{array}{l}20.87 \\
(18.98 \\
22.46)\end{array}$ & $\begin{array}{l}0.91(0.89 ; \\
0.93)\end{array}$ & $\begin{array}{l}0.76(0.58 \\
0.86)\end{array}$ & 0.005 \\
\hline & $\begin{array}{l}\text { Minor } \\
(\mathrm{n}=82 \text {; } \\
\text { REM-1) } \\
\text { Minor } \\
(\mathrm{n}=14 ; \\
\text { REM-2) }\end{array}$ & $\begin{array}{l}17.54 \\
(17.28 \\
17.67)\end{array}$ & $\begin{array}{l}0.79(0.75 \\
0.82)\end{array}$ & $\begin{array}{l}0.27(0.15 \\
0.33)\end{array}$ & 0.005 \\
\hline \multirow[t]{2}{*}{ Female } & $\begin{array}{l}\text { Adult } \\
\text { (n=42; } \\
\text { REM-1) } \\
\text { Adult } \\
\text { (n=42; } \\
\text { REM-2) }\end{array}$ & $\begin{array}{l}21.06 \\
(19.05 \\
22.24)\end{array}$ & $\begin{array}{l}0.91(0.89 ; \\
0.94)\end{array}$ & $\begin{array}{l}0.81(0.69 ; \\
0.86)\end{array}$ & $<0.001$ \\
\hline & $\begin{array}{l}\text { Minor } \\
(\mathrm{n}=37 \text {; } \\
\text { REM-1) } \\
\text { Minor } \\
(\mathrm{n}=4 ; \\
\text { REM-2) }\end{array}$ & $\begin{array}{l}16.72 \\
(15.30 \\
17.15)\end{array}$ & $\begin{array}{l}0.74(0.58 \\
0.76)\end{array}$ & $\begin{array}{l}0.29(0.18 \\
0.35)\end{array}$ & $<0.001$ \\
\hline \multirow[t]{2}{*}{ Male } & $\begin{array}{l}\text { Adult } \\
\text { (n=39; } \\
\text { REM-1) } \\
\text { Adult } \\
\text { (n=39; } \\
\text { REM-2) }\end{array}$ & $\begin{array}{l}20.87 \\
(18.83 ; \\
22.86)\end{array}$ & $\begin{array}{l}0.92(0.89 ; \\
0.93)\end{array}$ & $\begin{array}{l}0.71(0.53 ; \\
0.89)\end{array}$ & $<0.001$ \\
\hline & $\begin{array}{l}\text { Minor } \\
\text { (n=45; } \\
\text { REM-2) } \\
\text { Minor } \\
(\mathrm{n}=10 \text {; } \\
\text { REM-2) }\end{array}$ & $\begin{array}{l}16.32 \\
(15.39 \\
16.93)\end{array}$ & $\begin{array}{l}0.72(0.56 ; \\
0.75)\end{array}$ & $\begin{array}{l}0.19(0.14 \\
0.33)\end{array}$ & $<0.001$ \\
\hline
\end{tabular}

Legend: Q1 = 1st quartile; Q3 = 3rd quartile. Wilcoxon signed-rank test. Significance level $=5 \%$.

classification based on REM-1 and REM-2 are represented.

\section{Discussion}

Examination of the medial clavicular epiphysis is of particular interest to age estimation in living subjects [14] because the 

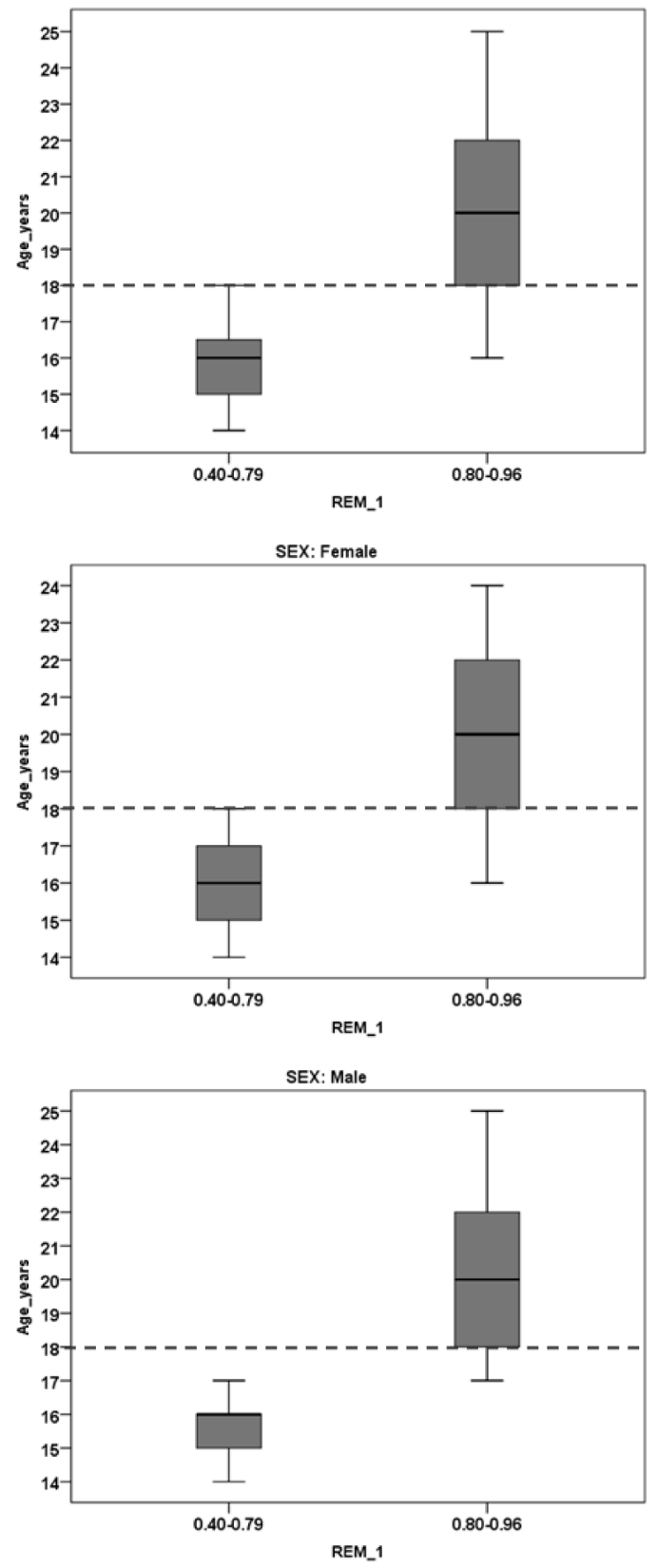
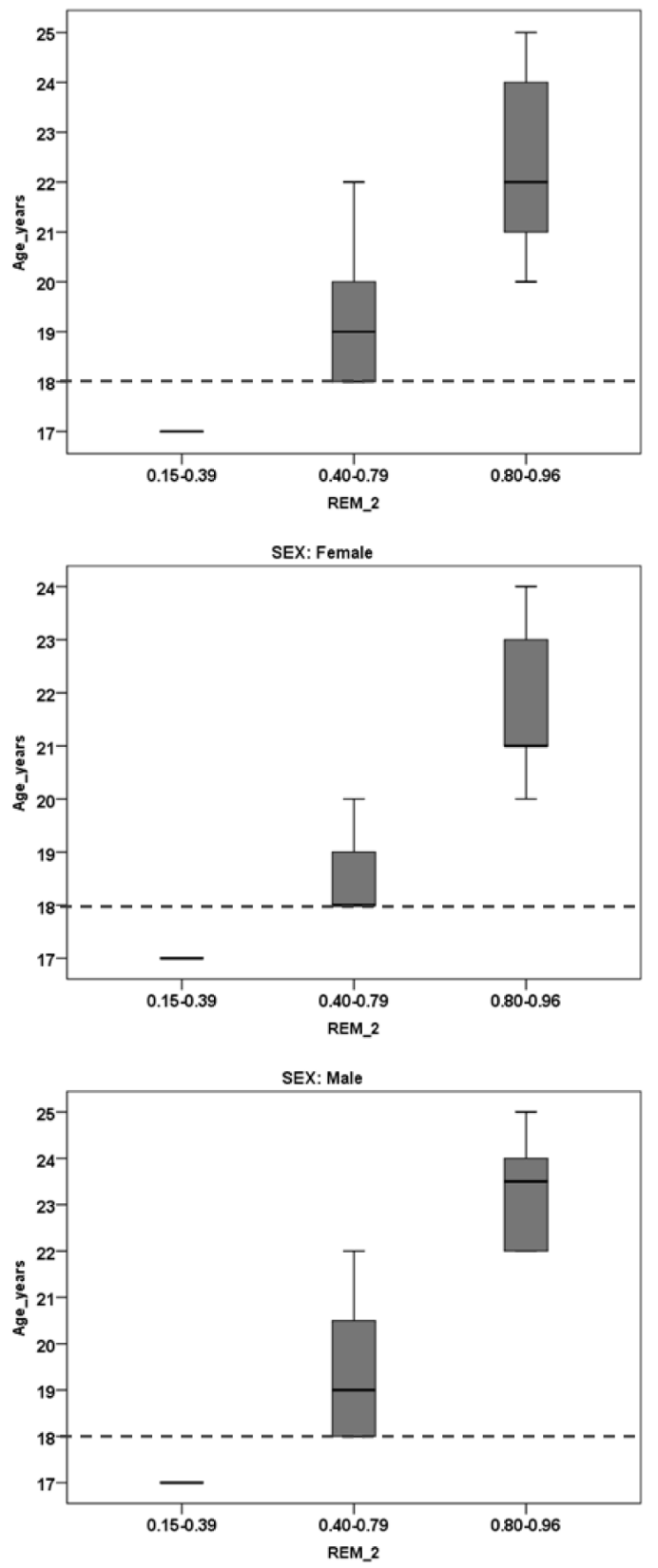

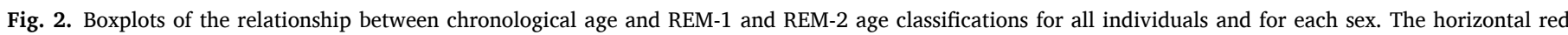
dotted line indicates 18 years of age.

sternoclavicular joint completes its development later than other anatomical regions.

In 2011, Hillewig et al. [15] proposed a study of the medial clavicular epiphysis in living people using MRI. In assigning developmental stages, less inter-observer variability was observed with the use of MRI compared to plain radiography. Without disregarding the difficulties associated with distinguishing between the different phases of ossification, the researchers concluded that $3 \mathrm{~T}$ MRI allows for more accurate determination of bone age than normal radiography, providing highresolution cross-sectional images of clavicle maturation in a very short time. This study led the same authors [16] to analyze a sample of 220 individuals by comparing the results of MRI (VIBE gradient T1 echo sequence, acquisition time $6 \mathrm{~min}$ ) using two different classification methods: those of Schmeling [4] and Kreitner [17]. The different phases were compared with the ages assessed by the Greulich and Pyle method (hand/wrist radiography) for the same individuals. Conditional probabilities determined that the chance of an individual with a stage 4rated clavicle being under 18 was $0.8 \%$ for females and $0.2 \%$ for males. Furthermore, the examiners were not always able to distinguish between the different phases (phase 1: absence of ossification center, absence of epiphysis; phase 4: complete fusion); it was therefore recommended that a hand/wrist X-ray be taken to correct this potential error.

In 2014, Vieth et al. [18] analyzed the stage of ossification of the medial clavicular epiphyses in 152 male footballers aged 18 to 22 years using 3 T MRI. The only footballer with complete ossification of the medial clavicular epiphysis was 21.2 years old.

In 2017, Schmidt et al. [19] conducted a prospective study on a baseline sample of 334 female and 335 male German volunteers aged between 12 and 24 years using 3 T MRI. Ossification stage IIIc offered a means in both sexes of demonstrating that the age of 18 had been reached before the complete ossification of the epiphyseal plate. For both sexes, if subjects presented ossification stage IV, it could be stated 


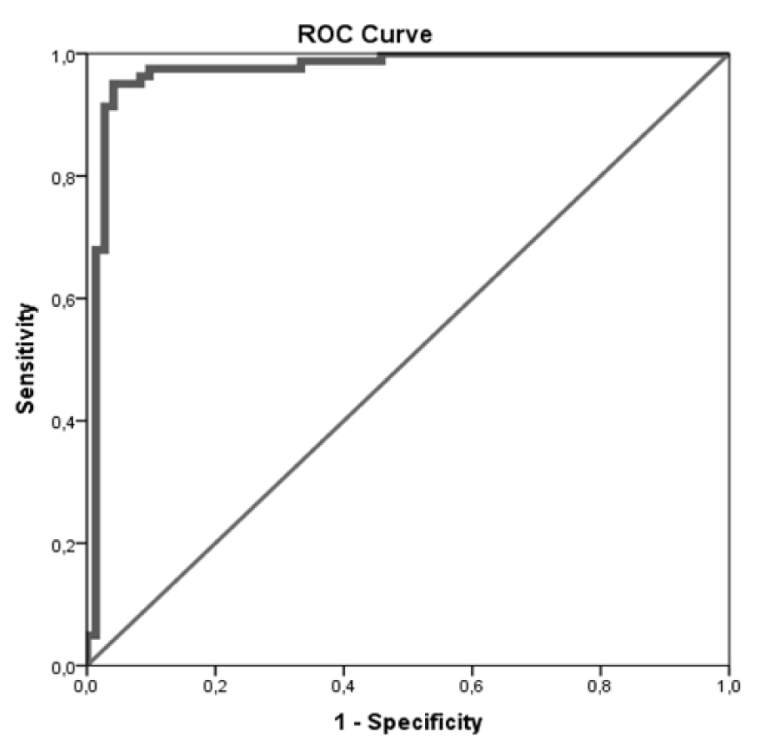

REM-1

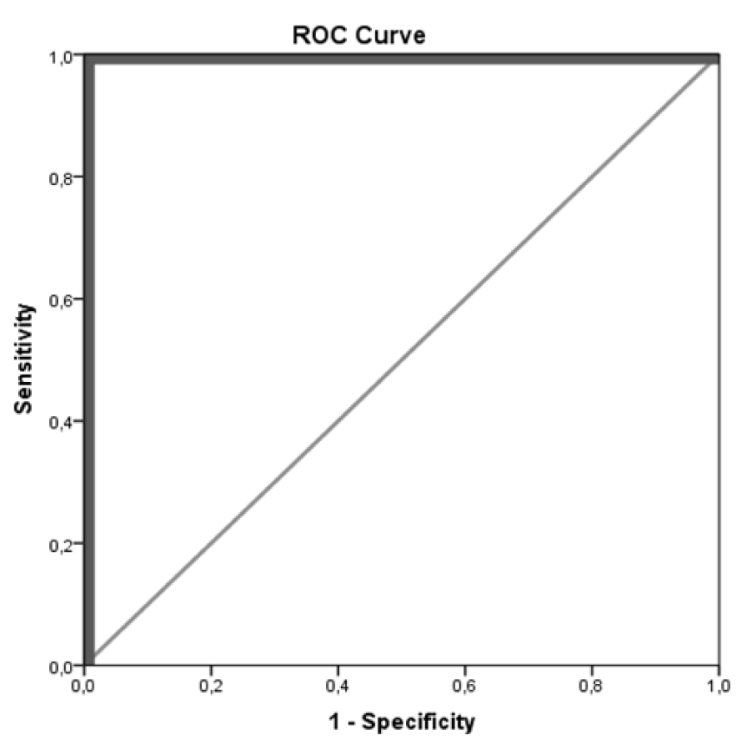

REM-2

Fig. 3. Receiver operating characteristic (ROC) curves for age classification (adult or minor) based on REM-1 and REM-2.

that they had reached the age of 21 .

More recently, Shedge et al. [20] developed regression models to estimate age by evaluating medial clavicular epiphyseal fusion in an Indian population using Schmeling et al. [4] and Kellinghaus et al.'s [9] methods, in order to assess whether an individual's age is over the medicolegally significant thresholds of 16 and 18 years. The degree of ossification of the medial clavicular epiphysis was studied in CT images of 350 individuals aged 10.01-35.47 years and a significant statistical correlation ( $\mathrm{p}<0.001$ ) was observed between the degree of fusion and the chronological age of the participants, with Spearman's correlation $(\rho)=0.918$ in females and $\rho=0.905$ in males.

The aim of our study was to generate a new cut-off point for age estimation by performing measurements of the medial clavicular epiphysis and metaphysis, then calculating two types of ratio: REM-1 (length of the whole epiphysis/length of the metaphysis) and REM-2 (length of epiphyseal-metaphyseal fusion/length of the metaphysis), using the operative approach introduced by Schmeling et al. and further modified by Kellinghaus et al. In our research, a statistically significant correlation between the medial clavicular epiphyseal joint and the chronological age of the individual was demonstrated. In particular, through our logistic regression model, better cut-off points for REM-1 and REM-2 were determined: for REM- 1 the cut-off values were 0.83 (for all individuals and males) and 0.86 (for females), whereas for REM2 , the cut-off scores were 0.40 (for all individuals and for males) and 0.41 (for females). Values equal to or above these cut-off points were statistically significant and used to classify the individuals as adults, while values below these limits were used to classify the individuals as minors. In particular, in our sample, when REM-2 could not be measured the individuals were classified as minors; in fact, it was possible to calculate a REM-2 in all adult individuals.

Observing the two ROC curves, it is clear that the best cut-off point to determine 18 years of age is represented by REM-2, which yielded maximum discriminative power. In the light of this, we can conclude that REM-2 is the most suitable choice for predicting the age of majority.

Our model obtained more accurate results than those of previously cited authors, thanks to three factors: the use of a high-resolution imaging tool; the selected approach of calculating a ratio between lengths; and the possibility of obtaining numerical data using specific software rather than score systems in which the evaluation of the ossification stages of medial clavicular epiphyses are exclusively operatordependent.
In conclusion, the strength of the method lies in identifying a minor or adult subject for forensic purposes, with a simple and immediate approach, considering two measurements (epiphysis and metaphysis) on the clavicular-sternal joint. In particular, the results allow us to state that:

- if for an individual we only have REM-1, he or she is certainly a minor;

- if we have both REM-1 and REM-2, the individual is a minor if REM-2 is showing values $<0.4$;

- in minors where REM-2 could not be calculated, the process of epiphysis-metaphysis fusion had surely not yet begun.

The limitations of the method are substantially related to the presence of possible artifacts in MR scans for various reasons, such as micromovements of the individual during the examination, hardware relatedfactors, texture characteristics, data acquisition and scanning parameters. In addition, it should be noted that the costs are inevitably higher than with an X-ray examination. However, if the MR images are of good resolution, we could get adequate measurements and satisfying results.

Further studies must be conducted in different countries to validate our MR approach for assessing 18 years of age in living subjects before considering the routine use of this method for forensic purposes. Nevertheless, it has been shown to be a valid diagnostic procedure, in an Italian sample, for determining a cut-off point for the age of majority, based on ossification of the sternal end of the clavicular epiphysis.

\section{Funding}

This research did not receive any specific grant from funding agencies in the public, commercial, or not-for-profit sectors.

\section{Declaration of Competing Interest}

The authors declare that they have no known competing financial interests or personal relationships that could have appeared to influence the work reported in this paper.

\section{Acknowledgments}

We would like to thank the Radiology Department of the Ospedali 
Riuniti of Ancona - Marche Polytechnic University - for providing the MR images. Thanks to Jemma Dunnill for correcting the manuscript.

\section{References}

[1] A. Schmeling, C. Grundmann, A. Fuhrmann, H.-J. Kaatsch, B. Knell, F. Ramsthaler, W. Reisinger, T. Riepert, S. Ritz-Timme, F.W. Rösing, K. Rötzscher, G. Geserick, Criteria for age estimation in living individuals, Int. J. Legal Med. 122 (6) (2008) $457-460$.

[2] R. Cameriere, L. Ferrante, D. Mirtella, M. Cingolani, Carpals and epiphyses of radius and ulna as age indicators, Int. J. Legal Med. 120 (3) (2006) 143-146.

[3] R. Scendoni, G.V. Zolotenkova, S. Vanin, et al., Forensic validity of the third molar maturity index (I3M) for age estimation in a Russian Population, Biomed Res. Int 2020 (2020) 6670590.

[4] A. Schmeling, R. Schulz, W. Reisinger, et al., Studies on the time frame for ossification of medial clavicular epiphyseal cartilage in conventional radiography, Int. J. Legal Med. 118 (2004) 5-8.

[5] J.A. Krämer, S. Schmidt, K.-U. Jürgens, M. Lentschig, A. Schmeling, V. Vieth, The use of magnetic resonance imaging to examine ossification of the proximal tibial epiphysis for forensic age estimation in living individuals, Forensic Sci. Med. Pathol. 10 (3) (2014) 306-313.

[6] Ekizoglu O, Hocaoglu E, Inci E, et al. Forensic age estimation via 3-T magnetic resonance imaging of ossification of the proximal tibial and distal femoral epiphyses: Use of a T2-weighted fast spin-echo technique. Forensic Sci Int. 2016; 260:102.e1-102.e7.

[7] R. Scendoni, M. Cingolani, A. Giovagnoni, M. Fogante, P. Fedeli, Y.I. Pigolkin, L. Ferrante, R. Cameriere, Analysis of carpal bones on MR images for age estimation: first results of a new forensic approach, Forensic Sci. Int. 313 (2020) 110341, https://doi.org/10.1016/j.forsciint.2020.110341.

[8] S. Schmidt, M. Mühler, A. Schmeling, W. Reisinger, R. Schulz, Magnetic resonance imaging of the clavicular ossification, Int. J. Legal Med. 121 (4) (2007) 321-324.

[9] M. Kellinghaus, R. Schulz, V. Vieth, S. Schmidt, H. Pfeiffer, A. Schmeling, Enhanced possibilities to make statements on the ossification status of the medial clavicular epiphysis using an amplified staging scheme in evaluating thin-slice CT scans, Int J. Legal Med. 124 (4) (2010) 321-325.
[10] R. Cameriere, S. De Luca, D. De Angelis, et al., Reliability of Schmeling's stages of ossification of medial clavicular epiphyses and its validity to assess 18 years of age in living subjects, Int. J. Legal Med. 126 (6) (2012) 923-932.

[11] W.S. Rasband, ImageJ, U.S. National Institute of Health, Bethesda, Maryland, USA, 1997-2018. http://imagej.nih.gov/ij.

[12] R Core Team, R: A language and environment for statistical computing. $R$ Foundation for Statistical Computing, Vienna, Austria, 2020. https://www.Rproject.org/ Accessed 13 May 2021.

[13] IBM Corp. Released 2019. IBM SPSS Statistics for Windows, Version 26.0. Armonk, NY: IBM Corp, 2019. https://www.ibm.com/ Accessed 13 May 2021.

[14] A. Schmeling, P.M. Garamendi, J.L. Prieto, M.I. Landa, Forensic age estimation in unaccompanied minors and young living adults, in: N.V. Duarte (Ed.), Forensic medicine-from old problems to new challenges, InTech, Rijeka, 2011, pp. 77-120, https://www.intechopen.com/chapters/19163.

[15] E. Hillewig, J. De Tobel, O. Cuche, P. Vandemaele, M. Piette, K. Verstraete, Magnetic resonance imaging of the medial extremity of the clavicle in forensic bone age determination: a new four-minute approach, Eur. Radiol. 21 (4) (2011) $757-767$.

[16] E. Hillewig, J. Degroote, T. Van der Paelt, A. Visscher, P. Vandemaele, B. Lutin, L. D'Hooghe, V. Vandriessche, M. Piette, K. Verstraete, Magnetic resonance imaging of the sternal extremity of the clavicle in forensic age estimation: towards more sound age estimates, Int. J. Legal Med. 127 (3) (2013) 677-689.

[17] K.-F. Kreitner, F.J. Schweden, T. Riepert, B. Nafe, M. Thelen, Bone age determination based on the study of the medial extremity of the clavicle, Eur. Radiol. 8 (7) (1998) 1116-1122.

[18] V. Vieth, R. Schulz, P. Brinkmeier, J. Dvorak, A. Schmeling, Age estimation in U-20 football players using 3.0 tesla MRI of the clavicle, Forensic Sci. Int. 241 (2014) $118-122$.

[19] S. Schmidt, C. Ottow, H. Pfeiffer, W. Heindel, V. Vieth, A. Schmeling, R. Schulz, Magnetic resonance imaging-based evaluation of ossification of the medial clavicular epiphysis in forensic age assessment, Int. J. Legal Med. 131 (6) (2017) 1665-1673.

[20] R. Shedge, T. Kanchan, P.K. Garg, S.G. Dixit, V. Warrier, P. Khera, K. Krishan, Computed tomographic analysis of medial clavicular epiphyseal fusion for age estimation in Indian population, Leg. Med. 46 (2020) 101735, https://doi.org/ 10.1016/j.legalmed.2020.101735. 